\title{
The research on China football reserve talent cultivation
}

\author{
Qiang Yan ${ }^{1, a}$ \\ ${ }^{1}$ Yulin University, Yulin, Shaanxi, 719000 \\ ${ }^{\mathrm{a}}$ email
}

Keywords: Football, Chinese, Reserves Cultivation Method

\begin{abstract}
Since the implementation of professional football, football has made some progress, but compared with our neighbors South Korea and Japan football, this progress is negligible, why do my football not increase? The reason is that football Reserves cultivation in China has not been paid attention. This paper study Junior Football Reserves cultivation mode for each football powerful country, discuss shortcomings of youth football reserves cultivation, advice and provide reference for the establishment of the reserves cultivation Mode.
\end{abstract}

\section{Introduction}

Football Occupation in China started late. In the 1980s, due to the impact of the World Cup several times, the Olympic defeat, football in the history of the worst trough. Under the planned economy system, because the provinces, physical culture and sports development strategy in the deviation to make football a serious shortage of funds, resulting in reduction of the team, football population decline, which reflect Hong football foundation is very weak. The early 1990s, the country's political system and economic reform, planned economy to a market economy transition restructuring trend, the Chinese Football Association after two years of planning and experimentation, in 1994, officially launched the Chinese Football League. After several years of hard work, football reforms have achieved initial results, the professional league has begun to take shape, the football club has been gradually standardized and football population has also been a significant increase in training young reserve forces is also improved.

However, because of the development of football has experienced ups and downs in the short term ideological transformation abrupt, short lead time, the reform of football science, scientific forecasting and decision-making efforts, lack of depth, the corresponding football rule of law, regulations are not sound, professional clubs standardization lack of aggressive league in on, as well as financial, material and manpower scarcity, the Chinese football League in the superficial prosperity masked, there has been a lot of problems and contradictions inevitable. On the whole, the level of Chinese football teams and the world still lags far behind, that is, within Asia, compared to South Korea, Japan, the three will never be the same level of the team.

\section{Football Reserves Cultivation Status}

1992 football management system, to promote the transformation of the country of football management mechanism, breaking the old planned economy system nakedness committee provinces, municipalities and football team competition, training management system, implemented with the club as the main competition, training management system. China's traditional three-tier management system training: Training Model Primary School a provincial amateur sports school a professional team. With the reform of football, football talents cultivation has undergone major changes: reducing the proportion of government investment, increase social investment ratio, changing the past alone single channel state funding to mobilize the community to do sports enthusiasm; the Reserve Talents increasingly rely on the market, the implementation of economic accounting, emphasis on investment returns, management at all levels of government, administrative departments of sports and football associations tend to be more to guide the organization, coordination and operational. So that the Football Talent Reserve Cultivation appeared 
in various forms coexist. In China's current diverse youth football reserves cultivation mode, there are four institutions:

Professional clubs (Super, a club) system, U-21-year-old, U-19-year-old, U-17-year-old and three reserve forces by the club sponsored children's football school training management system.

Provincial People's Liberation Army and the Profession Athletic Association National Games team and municipal representatives of the Games team training, management system.

At this stage in the administrative hierarchy based training system into a market-based training system. In addition to the existing National Youth amateur training, there has been training amateur form of business, personal and collective run. The main form of school football culture is amateur sports school, football Traditional Schools, Professional Football Clubs echelon amateur and youth football club. In the 1999 Chinese Football Association registered members always have table football schools, amateur football clubs, which appeared in a wide range of youth football reserve talent cultivation system.

Among the many culture institutions, professional football clubs in reserve forces is the main part of Reserves cultivation, amateur sports school, football school, traditional sports schools and amateur football club is an important part, is to develop overseas player football talents an effective supplement form. For studying abroad, the Chinese Football Association has no clear plan selected.

\section{Main Problems in Reserves Cultivation}

Youth football countries in the world recognized as the basis for the development of football and hope echelon training of youth football is the key to a country's level of competitive football talent development. In our efforts to develop youth football career always in slogans, put into practice enough. Performance is more in the actual operation of profit-oriented thinking. Overall development back on athletics, light spread, ignoring the Junior Football Training tasks, under funding constraints, the system behind reality, youth football at the grassroots level teaching, training investment is stretched, youth football in many places a serious recession, the fundamental does not meet the required adult team reserve forces, so that the masses of the development of football and athletics as a basis for the level of football are deeply affected.

Currently, young football players a lot of time and effort to carry out individual technical training, and on the overall training too little, it deviates from the actual content of training and competition. Therefore, in the course of the game will be present to hear the coaches telling them: To play brains, feet a little faster. In fact, the team would also like brains, but also want a little faster, but also do not want to miss. However, the coaches in the usual training, what kind of a way for the players brains? And what kind of way can we get the foot players a little faster? To solve this problem we need some coaches training methods, through training so players reach a habit, habit formation, and players in the field will be able to show it. No reasonable and effective training methods, it is impossible to athletes training content completely freely in the game used in the course of the game.

Throughout European football and Asian football powerhouse rapidly developing countries is not without knowledge of the culture of youth football training and youth learning closely, football training process never got out of cultural learning, training young football players is a gradual process. In China, football players from an early age began Football skills of learning, but they ignore its basic culture of literacy, they are incomplete in terms of culture and education. Let them write training diary typo talk, and technical and tactical aspects of what new breakthroughs do? Lose the game or lose, should not lose or lose.

Chinese football has always had technology is the core technology is the first thought, Chinese young people put a lot of time and effort to carry out technical training, but lost each time to the adult contest concluded or as good as people. Teenagers usually use most of our technical training, tactical training and actual arena is too small, too much emphasis on physical training. Training young people should follow the law of football training, purposeful, planned conduct. For the training of young people, the adults will be football-related requirements are divided into smaller short-term goals. 


\section{Football Reserves Cultivation Countermeasure}

In the new model, amateur sports schools in the past from the perspective of their own point of view and in terms of social impact and will gradually withdraw from the stage of history Reserve Talents, or turn to change the nature, another way to contribute to the work in youth sports. Primary children in the new model is an amateur football club and the local primary school football team, set up in favor of children's football school class with a variety of full-time training network, so that the child can have more time and energy into the basic course of study. Amateur football clubs must do business with a local professional clubs, professional clubs in which children regularly coaches amateur club, children's guidance. Local primary school football team also recommends that such operations.

Strengthen the Chinese Football Association and local football reserves cultivation functions of the management system. Football Association youth culture can not "walk away", to real realistically tube, the Football Association at all levels should strive to be: in the local region, actively organize various football activities to further promote the popularization and development of football, expanding football population, to create a good football environment: vigorously carry out primary and secondary schools football, football continues to train and reserve personnel; the development of youth and amateur football club football school actively cultivate talented football reserve talents both ability and integrity; to develop training programs and youth development Annual plan.

Under the socialist market economy, to fully mobilize social forces and public opinion, on the one hand through Elite Athletes children publicity, recognition, in order to mobilize the enthusiasm of young children to participate in amateur sports schools, transition Amateur Football Training bad ideas; on the other hand, to study as soon as possible and properly resolve the sports students education, employment and other outstanding issues, improve convergence project counterparts, so that staff up smooth delivery, training of all types of self-contained to ensure that all levels of amateur football training health and sustainable development.

Establish reasonable talent system. "Prime time" player in China's current system of competition is an inevitable problem for them is to be given adequate funding and match as much as possible to make them worthy of this title. Hence there are problems and faults, it should be done by the Football Association and the club around and Reserve Force departments jointly consultation. Chinese Football Association may be made mandatory: Local Football Association concentrating on prime-time players, clubs and football schools at all levels throughout the prime-time players and the intermediate gear grasping. The only way to ensure the World Cup national team players have more reasonable age of configurations.

Consolidation around the youth football clubs and football schools is meaningful. Developed jointly by the education sector and all kinds of sports administration football school assessment system, from time to time to check for those "but money is the map" schools, they are eliminated. Because youth football "aristocratic" tendency, it is necessary to existing youth football clubs and football schools conduct a rectification. Encourage investment-oriented youth football clubs and football schools, the way contracts and contracts for promising young football players to invest until after the players finished product to recover the investment cost by way of transfers. In order to ensure the interests of investors, we must standardize the system of transfer of young players, players prohibit digging, disrupt teenagers player transfer market. Chinese Football Association to the best youth football clubs and football schools tilted in the support policies to reward way from these funds and in-kind football clubs and school support.

Establish and improve the training system of youth football as soon as possible. Chinese Football Association is tread as the leading member associations around the main body, facing the country youths grassroots amateur training units, to build a youth football training system with Chinese characteristics. The system has a full-time, the person responsible from the development of competition regulations and training and teaching training program, selection and training of young football players at all levels have to respect the coach's training, the formation of a system of long-term stability to carry out the implementation of it, out of a country football Reserve talents 
"of the Chinese type of youth football development path."

\section{Conclusion}

Training talented strategy is the development of competitive sports, only the importance of team building reserve personnel, the national sports development will be rewarding. In order to maintain the level of continuous improvement of a project, we must follow the laws of its own development and growth law of talents and solidly improve the training of reserve personnel. So, what is the level of the existing football Reserve Talents method, what are the problems to be solved in personnel training? All of those issues are worthy of discussion and analysis.

\section{References}

[1] Angela Iumpkin, Sharon Kay Stoll, Jennifer M. Beller Sport Ethics. Applications for Fair Play 2003

[2] Janet B. Parks. Contemporarv Soort Management, 2003

[3] David Kirk, Trish Gorely. Challenging thinking about the relationship between school physical education and sport performance European Physical Education Review

[4] Ron de Heil, Patrick Vermeulen. Strategic Actions in European Football the Service Industries Journal, 2006

[5] KevinMc shane. Coach youth football. The Europemo, 2002 